\title{
INTRODUCTION
}

\section{A grammar of law in context and action}

This book aims to deal with law and judicial activity, in their moral dimension as well as when they are faced with questions of morality. The context of this study is a specific one: that of public prosecutors' offices and courts of justice in Egypt, as well as the cases brought before them in the past ten to fifteen years. The intention, however, was neither to present the Egyptian legal system nor to take that system as a case study of a larger entity - which some might call "Islamic law". It was even less to postulate any form of Arab or Muslim cultural specificity. On the contrary, this book's goal is to observe the contextualized deployment of various practices, and the activities of very diverse people who, in different capacities, found themselves involved in or faced with institutional judicial space. More specifically, the objective was to observe and describe, in an empirically documented and detailed manner, the moral dimension of judicial activity, and the judicial approach to questions of morality. In other words, the point was to detail the production and manifestation of judicial activity in its necessarily moral dimension, and to examine how that activity mediates and modulates the treatment of cases dealing with sexual morality, among others.

To state that this is a study of law in context and action clearly specifies the perspective within which the work is situated. Inspired by the later Wittgenstein and aligned with ethnomethodology and conversation analysis, this perspective may be described as praxiological. In the following chapters, there will be abundant reference to works of ethnomethodology and conversation analysis, in general, and to the analysis undertaken by some of these works of legal and judicial objects, in particular. This introduction will be restricted to a general presentation of the ethnomethodological way to proceed and a few of its fundamental axes: the respecification of sociological objects; the attention paid to the practical grammar of actions, notably acts of language; the rejection of sociological irony and overhanging stance vis-à-vis the people and the actions they undertake. Having posited these basics, it will be possible to sketch out the general lines followed in the book.

\section{Ethnomethodology}

The invention of the term "ethnomethodology" must be attributed to Harold Garfinkel, who explained the conditions under which the term emerged (Garfinkel, 1974b). It was necessary to designate the study of the ways (the "method" part of ethnomethodology) in which people 
(the members of a given "ethnic" group: the "ethno" in ethnomethodology) give meaning to their world of action, orient to this world, and practice it in a routine manner and on a daily basis. In other words, ethnomethodology is concerned with the "procedures" by which actors analyse the circumstances in which they find themselves, and conceive and implement modes of action (Heritage, 1984: 9).

It would be impossible, here, to go back to the Parsonian counterpoint or the phenomenological contribution that did so much to determine the genesis of ethnomethodology. Suffice it to say, as John Heritage did (1984: 33-34), that Garfinkel, although he was Parsons' student, opposed Parsons on every essential point in his sociology, and particularly on the idea that modelling courses of action could be a pertinent way of studying social activity empirically, or that it could serve as a standard by which to measure the more or less rational character of actions people undertake. He also opposed the idea that norms and rules constitute factors that constrain people's behaviour in a deterministic way. As for the contribution of phenomenology, it comes through in the constant concern for taking into account people's "natural attitude" - the expression used by Edmund Husserl to designate the "worldly" framework through which we apprehend, perceive, and interpret the world in which we live, and through which we intervene in it. Alfred Schütz's influence, and his sociological adaptation of Husserl's philosophy, must be emphasized in this regard (Cefaï, 1998). For that author, the social world is experienced, first and foremost, through interpretation by those who live in it, as something intelligible and meaningful, in the form of social categories and constructs (Schütz, 1990; Cefaï, 1994; Coulon, 1994a). But it is the idea of ordinary knowledge having an intersubjective character and, more specifically, of insertion in a game of reciprocal perspectives - and the resulting idealisations: the interchangeable nature of points of view and the congruence of systems of pertinence - that constitute the main elements in Schütz's sociology. These types and categories, once Garfinkel and Sacks, among others, revisited and transformed them, became one of the cornerstones of ethnomethodology (see among others Watson, 1994).

In ethnomethodology, social facts are seen as practical achievements. In that perspective, Durkheim's aphorism - that social facts are objective reality - was, for Garfinkel, a constant source of inspiration and disputation. In Studies in Ethnomethodology, he pointed this out: 


\section{Baudouin Dupret}

... the objective reality of social facts as an ongoing accomplishment of the concerted activities of daily life, with the ordinary, artful ways of that accomplishment being by members known, used, and taken for granted, is, for members doing sociology, a fundamental phenomenon. (Garfinkel, 1967: vii)

His most recent book goes further, extending Durkheim's metaphor and using it as its cornerstone (Garfinkel, 2002). In this perspective, the objective reality of social facts becomes the group of themes that can be linked, in each concrete case, to an indigenous production of order, carried out locally, generated through collaboration, and describable through natural language:

Produced in a concerted manner by population cohorts, these phenomena of order are intelligible, recognizable, and recognized. They correspond to practices of production, monstration, observation, and recognition. (Garfinkel, 2001: 440)

This sort of concern for the way in which people conduct their methodical activities, establishing pragmatically what may be considered adequate, precise, and appropriate, supposes that the analysis rejects the search for external criteria in the establishment of truth and intelligibility (sociology's methodological discourse) and focuses only on the ordinary modes of practical sociological reasoning. This is what Garfinkel's call for "ethnomethodological indifference" means:

'Scientific methodology' [, 'm]ethods' (whether avowedly scientific or not) do not provide a priori guarantees, and the initial requirement for an ethnomethodological investigator is to find ways to elucidate methods from within the relevant competence systems to which they are bound. (Lynch, 1993)

Among the terms one encounters frequently in ethnomethodological literature, four deserve particular attention: accountability, the documentary method of interpretation, indexicality, and reflexivity. The first suggests both the account and responsibility. Contrary to the theory of correspondence, for which language exercises the function of representing reality, ethnomethodology asks what people do in action and through the action of accounting for something. Rather than speaking in terms of incorporation, habitus, self-mystification, lies, or double-speak, ethnomethodology considers that people are generally able to know and describe their daily business in a competent and adequate manner. Far from being idiots or dopes (in cultural, "judgmental”, or cognitive terms), people generally act and speak in and of their world in an informed way. In so doing, they describe it and orient intersubjectively towards this description, its relevance, and its intercomprehension. Accounts, in this 
perspective, are the manifestation of emergent relevancies to which consequences are attached, retrospectively and prospectively.

The prospective and retrospective meaning that people give to the events they account for is behind what Garfinkel (1967: 77-79) calls the documentary method of interpretation - the second important term in ethnomethodological literature. This is the method anyone uses to understand the events or objects of the world, as an underlying schema used prospectively to give meaning to future events, and, because judgments are always subject to revision, retrospectively as well, so that meanings of past events can change (Travers, 2001: 353). To say that someone is insane, for example, is at one and the same time a retrospective judgment on his past actions and the prospective basis on which to evaluate his future actions. The concept of a documentary method of interpretation, taken from Mannheim, thus refers to the use of a structure or an underlying model by its members simultaneously with its practical actualization. In this way, ethnomethodology is concerned with '... the way in which these models are apprehended by the members themselves at the moment of their particular situational manifestations.' (Watson, 2001: 21).

This leads us to observe that accounts made by the members of a given social group are irreducibly contextual, in the sense that they are loosely adapted to the events they describe, that they are subject to ad hoc adjustments, and they are understood by reference to a mass of postulates which are not made explicit (Heritage, 1984: 141).

This orientation of accounts to the context of their production, the fact that they point toward this context, is what Garfinkel calls their indexicality. Ethnomethodology is not the only method concerned with deictic terms, those which point towards their context. Still, Garfinkel, along with Harvey Sacks, placed the indexicality of accounts at the very heart of sociological work (Garfinkel and Sacks, 1986). The central question raised by indexical terms is due to the fact that they refer to different things according to the circumstances in which they are formulated. This problem is not at all limited to the correspondence between an indexical term and an indexed object, but rather extends to every descriptive action. The version of indexicality that Garfinkel proposes thus consists of showing [that] 'the intelligibility of what is said rests upon the hearer's ability to make out what is meant from what is said according to methods which are tacitly relied on by both speaker and hearer. These methods involve the continual invocation of commonsense knowledge and of context 
as resources with which to make definite sense of indefinite descriptive terms.' (Heritage, 1984: 144)

In a manner closely linked to indexicality, ethnomethodology is particularly concerned with analysing the reflexive character of social practices. According to Garfinkel, '[n]ot only does common sense knowledge portray a real society for members, but in the manner of a self fulfilling prophecy the features of the real society are produced by persons' motivated compliance with these background expectancies.' (1967: 53)

The notion of reflexivity thus refers to the fact that, as soon as they are formulated, our descriptions of social things become an integral part of what they seek to describe. Reflexivity therefore designates practices that describe and constitute a social framework: '... This is the property of activities that presuppose simultaneously their ability to reveal the same thing to observation.' (Coulon 1987: 37)

\section{Conversation analysis and the ethnomethodological study of work}

Ethnomethodology cannot be conceived of as a monolithic tradition. Among its ramifications are the phenomenological branch, incarnated mainly by the works of Melvin Pollner on “mundane reason" (1987); ethnographic ethnomethodology or the ethnomethodological study of work, essentially represented by the "second Garfinkel" (Ethnomethodological Studies of Work, 1986); and, finally, conversation analysis, incontestably initiated by Harvey Sacks (Lectures on Conversations, 1995). We will not dwell on the first of these trends for the time being, except to note that it was the subject of an interesting critique from within the ethnomethodological family (Lynch, 1993: 35-8; Lynch and Bogen, 1996). For now, we will focus on conversation analysis and the ethnomethodological study of work.

Conversation analysis originated in Harvey Sacks's attempts to lay the foundations for a sociological method that would be able to grasp the primary data of the social world. In that sense, Sacks sought to deal with the details of natural events in a way comparable to that of the primitive natural sciences - in such a way that non-specialists could narrate them by going into the field, observing what took place there, and describing it in vernacular terms (Sacks, 1995, vol. 1: lecture 33). From this stemmed the idea that one way, or even the only way, allowing to obtain stable descriptions of courses of human action consisted of narrating the methods and procedures used to produce these courses of action (Schegloff, 1995). This becomes possible because commonsense actions are methodical, or in other words ordered, 
describable, recognizable, and reproducible (Lynch, 2001b: 265). They result from ordinary, usual, routine interactional skills, which are structurally organized and contextually oriented. Ordinary linguistic interaction can therefore be analysed in such a way that stable schemes organizing action, to which participants orient, begin to emerge (Heritage, 1984: 241). Conversation analysis thus brings out the fact that every act of communication is shaped by context, and simultaneously shapes this context. Further, conversation analysis underscores the ordered character of linguistic interaction: participants produce regularities and orient to them as normative grounds for action and inference (Heritage, 1984: 244).

Several major recurrences emerge in conversation analysis: first, the sequential organization of the conversation, by which Schegloff and Sacks (1973: 295-6) mean the fact that each utterance accomplishes a certain number of precise tasks in the course of a conversation, by sole virtue of its placement and its participation in a sequence of actions that are generally organized in adjacent pairs (question-answer, request-acceptance or refusal, invitation-acceptance or refusal, etc.). This sequential structure is normative: the first part of a pair (for example, a question) normally conditions its second part (for example, an answer). Any breach on this "conditional relevance" must thereby be justified. Conversely, the first part acquires significance only when the second part is uttered; in turn, the second can be sure that it is adapted to the first only when it is ratified by the first participant, pronouncing the third utterance. Conditional relevance is also subject to orders of preference (for instance, acceptance of an invitation is preferable to rejection). Finally, note must be made of the conversational context in its institutional dimension, and of all its consequences for the system of turns in conversation, the organization of participants' behaviour in interaction, its subjective perception, the organization of procedures, lexical choices, the routines of professional participants, and the asymmetry between professional and lay participants (Drew and Heritage, 1992).

The ethnomethodological study of work constitutes a third ramification of ethnomethodology, which it is important to discuss at this point, given that it occupies a central place in the method followed in the present work. This development of ethnomethodological research appeared as a critique of labour sociology and its tendency to ignore or to idealize the technical dimension of professional activities. Faced with a "missingwhat", the ethnomethodology of work invited researchers to focus on the "just-this-ness" of activities in places of work, on their specifically practical dimension. This was, then, an invitation to observe and describe what practitioners do and how they understand what they 
do as they carry out an ordinary professional task (Travers, 2001: 360; see also Lynch, 1993: ch. 7). As Michael Lynch emphasizes (1993: 270), there is a vast gap between the methods used to study professional activity and the methods that make up the "what" (or, as Garfinkel termed it, the "quiddity") of the practices themselves. A good example of this is a certain type of legal sociology: the form that is more concerned with denouncing the injustice and inequality of law than with describing its practical deployment. In line with this project, Garfinkel called for the acquisition of dual skills, where mastery of a practical discipline would be combined with skill in ethnomethodology. The point was, in a sense, to encourage the hybridization of ethnomethodology with other disciplines. There is, however, a danger that consists of seeing each specialized discipline as a unique set of practices, defined by a singular essence to which access is determined by a strategy aiming to gain entrance into its epistemic circle. As Lynch points out, '[i]f we were to suppose that ethnomethodology could become an epistemic center from which inquiries into all other disciplines could be conducted, we might conclude that Garfinkel's ambition was to build a science capable of grasping the genetic essence of each praxiological species.' (1993: 276)

Garfinkel, who was aware of the risk inherent in such ambitions, abandoned the use of the term quiddity and instead used "just-this-ness". Although both terms can serve to designate "what makes an object what it is uniquely," "just-this-ness" emphasizes an indexical dimension in the construction of meaning that is free from any essentialism. Rather than producing accounts of accounts and documents abstract of the concrete, experienced operation that produces them; instead of dissociating documents from the activity that consists of producing documents, ethnomethodology of work attempts to grasp both parts of the pair (document and documentary activity) simultaneously, in the belief that they are indispensable to each other and indissociable from each other for a proper understanding of the phenomenon under consideration (Livingston, 1987; Lynch, 1993: 287-299).

\section{Irony, respecification, and praxiological grammar}

Ethnomethodology thus posits itself as marking a clear break with sociological tradition. This position is expressed in its rejection of any position that would give sociologists a privileged vantage point on the world. Ethnomethodology has thus been led to respecify objects of sociological study. Finally, it has engaged in analytical study of the practical grammar of contextualized saying and doing. 
Ethnomethodology and conversation analysis reject the form of irony that characterizes most sociology, placing the researcher "above" social and legal reality, and thereby claiming to grant a monopoly on understanding of what is "really" going on - and which actors could not see for themselves. The conventional approach thus tends to consider that, in a general framework where one recognizes the naturally perspectival character of social phenomena, it is appropriate to seek a perspective free from those adopted by social actors. In other words, sociology is required to find a position from which it can observe both impartially and holistically - observe, indeed, in a way that transcends worldly contingency; or, at least, when it is recognized that the transcendental point of view cannot be reached, it attempts to correct as much as possible the biases introduced by the perspectival nature of social phenomena. As for ethnomethodology, it approaches matters differently. Rather than adopting a corrective position, whereby it might attempt to attenuate the consequences of perspectivism, it focuses on this perspectivism in and of itself, as a dimension inherent to social and scientific activity. As Wes Sharrock and Rod Watson, adapting Heidegger, emphasize, sociologists are projected into the heart of the phenomena they seek to analyse. As a result, from the outset, any investigation is inevitably intertwined with the phenomenon it examines (1990: 229). Furthermore, sociologists cannot undertake their investigations outside their own common sense and background expectations as (competent) members of their society: to be able to propose anything regarding the events observed in social situation, sociologists must necessarily mobilize some degree of common sense understanding (ibid.).

It is therefore not sociology's task to overhang social reality, regarding it ironically, as if to say: I will reveal to you things that have been hidden since the world was created, thereby supposing that 'the meaning of social behaviour is inaccessible to the actors and reserved exclusively to those who can use certain tools of analysis.' (Livet, 2001: 422)

Sociological research cannot situate itself outside time or place. The analytical framework it proposes does not aim to compete with that of ordinary members of society. In that sense, there is no room for a "Goffmanization" of the world, in the words of Edward Rose (personal communication to Watson, 1998), which, by suggesting a dramatization of people's activities, waxes ironic on the ways in which they proceed, supposes that they are constantly setting the stage, and imputes to all the acts of anonymous, interchangeable actors supreme primary motives (Watson, 1998). 
Ethnomethodology's refusal of an overhanging position is based on two corollary principles, among other things: a critique of the ambition to construct theories that propose global social models, and the principle, evoked early, of ethnomethodological indifference. The humanities and social sciences generally seem to emerge from a single epistemological and methodological matrix that incites theorizing, professional scepticism, and the application of mathematical reasoning to social phenomena (Button, 1991: 4). In contrast, ethnomethodology affirms that it is impossible to isolate a question from the circumstantial details that surrounded its emergence. Constructing grand explanatory models is classically tantamount to articulating empirical data and an abstract model in a system of correspondence. The problem arises precisely from this idea of correspondence between the model and events that are apprehended as instances of the model. As Douglas Benson and John Hughes (1991: 119) emphasize, however, even when researchers face no particular difficulty in classifying a phenomenon, they put this classification in action by using and paying attention, for the purpose in hand, to unexplained characteristics of the case, event, or person under observation. Once the purpose in hand changes, the relevant elements change as well, and other classifications are established. By referring to local situations as instances of a general model, researchers can ultimately hide the fact that a single word, for example, can mean very different things in very different contexts. One thus reaches authoritarian processes of categorization, where the relation between observation and observed object is presumed on the basis of postulates concerning both the model and its instances. The result is that one only knows what phenomena resemble through the prism of a format one has imposed upon them; but one knows very little with regard to the phenomenon's properties underlying this format (Benson and Hughes, 1991: 121). The very object that is supposed to be under study then becomes a mere function of the format imposed and of the implicit theory adopted by the researcher, rather than being a research object in and of itself. It is at this level that the idea of ethnomethodological indifference has a place. Rather than wondering whether sociologists can find identifications and characterizations of the phenomena they study that are adequate and acceptable in comparison to a given grand scheme, it is necessary to find out whether the members of a given social group identify and characterize something as an instance of something else (Lynch, 1991: 86 et seq.). Instead of searching for correspondences between the model and its instances, ethno-conversational analysis seeks to respecify its object in a manner leading it to observe, describe, and understand how people use categories in accomplishing their activities so as to make the world recognizable and subject to organization in a way that is relevant to them. Phenomena are no longer interpreted, then, 
according to a grid that we might impose upon them. Such a description cannot be carried out with abstract models that are external to the phenomena under study - herein lies the risk of irony and the overhanging attitude emphasized above. On the contrary, it is necessary to presume nothing theoretical with regard to phenomena, beyond their empirical description. In consequence, the social scientist's task is no longer to find the model of which such and such an event is the instance, but instead to try to find the social mechanisms that produced the event as it occurred.

Ethnomethodological respecification pledges the researcher to study the practical or praxiological grammar of contextualized doing and saying. In a perspective inspired by the later Wittgenstein (1961: §7-24 et seq.), it is necessary to study language games, in which linguistic usage and practical behaviour are seen as intertwined in a complex manner (Coulter, 1991: 27). Among Wittgenstein's favourite targets were "grand concepts", like the "mind", constructed as floating entities, totally decontextualized and retroactively projected onto the world as if they were its very nature - as if they were "something beneath the surface" (Wittgenstein, 1961: §92) independently of their actualization or the context in which they are used. In language games, '[g]rammars of concepts are rules which not only specify the linguistic frameworks within which words, phrases or types of words or phrases may be used, but also "what counts as an application of" such expressions. Grammars reveal the manifold connections between words and other words, phrases and expressions as these are used by "masters of natural language", and the manifold connections between kinds of expression and sorts of circumstance within which and about which they may be used.' (Coulter, 1989: 49)

For Wittgenstein, carrying out a grammatical investigation was a means of eliminating '[m]isunderstandings concerning the use of words, [misunderstandings] caused, among other things, by certain analogies between the forms of expression in different regions of language. - Some of them can be removed by substituting one form of expression for another...' (Wittgenstein, 1961: §90)

A word's grammar, therefore, refers in a descriptive (and not an explanatory: id.: §496) manner to the modes of usage of that word. To investigate the grammar of concepts - legal concepts, in our case - therefore supposes inversing the tradition manner of doing research. Traditional philosophy easily incites one to give an essentialist significance to terms that have strong resonance, like "to know", "to represent", "to reason", and "true". It leads one to hypostasize concepts like "knowledge", "representation”, “reason”, and "truth". Researching 
the grammar of concepts, in contrast, allows us to problematize epistemology, by showing, in the daily use of "epistemological" expressions, variations, systematic ambiguities, and manifest sensibilities (Lynch, 1993: 199).

The description of situated activities that accomplish an epistemological task (for example, knowing, deducing, and finding causes) makes it possible to see the relevance the concept takes on in certain activity contexts. Respecifying sociological methods and analyzing the practical grammar of epistemological concepts lead us to what Michael Lynch has called a study of "epistopics". This means that instead of participating in the construction of metatheoretical terms, on the basis of which the social sciences are elaborated, it is necessary to pay attention to these terms as "words" implicated in language games, and to examine the occasions on which such language games are practiced. In other words, it is necessary to examine the situated uses of epistemic themes, starting from the principle that nominal coherence alone (the use of the same word in different contexts) guarantees nothing with regard to the uses of that word. Quite the contrary: to return to the theme of quiddity advocated by Garfinkel, it is the irreducibly unique character of each occurrence that must be emphasized. In conclusion, Michael Lynch (1993: 265-308) thus suggests that investigations be carried out that begin with identifying epistopics, and then seek to follow their trail in various real cases of deployment, using ordinary words of observation, description, comparison, and reading.

\section{The morality of law and the law of morality}

This book seeks to respecify legal objects, in the moral dimension of their deployment and in their treatment of moral questions. To that end, we will start by attempting to lay the foundations of a praxiological approach to relations between law and morality. Next, we will examine judicial activity and the moral organization of its exercise. Thirdly, we will deal with the practical grammar of a few major questions of law. Finally, a fourth part will focus in detail on a legal case that bore on a question of morality.

It is difficult to perceive the entire value of the praxiological approach without bearing in mind the background and the counterpoint of the traditional way of dealing with relations between law and morality. Philosophy of law progressively established the positive status of norms by detaching them from their metaphysical anchors. From then on, moral norms were distinguished from legal norms. This is no doubt one of the fundamental principles on which 
modern law is based. Thus, for Herbert Hart, nothing makes it necessary to consider that legal rulings correspond to or reflect certain moral exigencies. Ronald Dworkin, for his part, impugned the positivist distinction, asserting that law, rather than a simple system of rules, is a combination of rules and principles. Dworkin thereby reintroduced morality as a major component of the legal phenomenon. This substantivist perspective, however, fails to resolve a major question: how are these principles constituted, mobilized, and characterized? In a way, Dworkin's substantivist approach, while claiming to reintroduce morality in law, sheds no light on the very phenomenon it is supposed to deal with: the modalities of law's moral dimension.

Grasping the moral dimension of the law in its practice implies envisaging, in a prejudicial way, what one could follow John Heritage in calling the morality of cognition. This expression suggests that the activities of competent members of a given social group are thoroughly imbued with a normative element, based on a certain number of background expectations that are realized, ratified, or contradicted. In turn, these expectations serve as a basis for other subsequent actions. This normative interaction, whether banal or extraordinary, is based on "mundane" ways of reasoning, understanding, interpreting, categorizing, and inferring, all of which orient to an intersubjectively constituted horizon of normalcy. Such normalcy, whether it is based on the nature of things or the things of nature, is a continuous achievement, with no time out, which permanently actualizes underlying shared schema of interpretation, projecting them in turn into the future, in the very thread of interaction, so that these relevancies are always already there and emerging.

The third chapter will deal with law in action. It will seek to synthesize works that have concerned legal objects in the ethnomethodological tradition. Law and justice, since the early works of Garfinkel and Sacks, have held a privileged place in ethnomethodology; the practices of various legal actors - lawyers, police officers, prisoners, jury members, judges, etc. - have provided the basis for the study of activities and language in context. In this perspective, the point was not so much to identify the defects of these practices in comparison with an ideal model or a formal rule to which they should have conformed, but rather to describe the modes of production and reproduction, the intelligibility and comprehension, the structuring and public manifestation of the structured nature of law and the different activities linked to it. Thus, rather than positing the existence of racial, sexual, psychological, or social factors, ethnomethodology and conversation analysis examined how activities are organized 
and how people orient to the structure of these activities, which can be and are read in a largely unproblematic way.

The second part of this book is concerned with legal and judicial activity in context. The first chapter will examine the judicial context. Action, understood as speech acts, cannot be understood in a vacuum, outside the locus of its production. Questions of identity and meaning, for example, depend strictly on the context in which they emerge and on the linguistic activities in which participants engage. In the course of interactions, people publicly manifest contextual relevancies to which they orient, as well as their understanding of these relevancies and their implications for subsequent actions. This contextual constraint is not a static given of interaction, but rather a reflexive and fluctuating framework, which members of the legal setting continuously reevaluate and according to which they carry out constant realignments. Linguistic expressions are conceived and formed for the purpose of intervening in particular sequential and social contexts, in a manner that is publicly recognizable and intelligible. This contextuality can also take on an institutional dimension, translated, in an empirical manner, through linguistic activity oriented to specific ends, modeled according to particular constraints, and inscribed within determined inferential frameworks and procedures.

Next, we will examine the effects of procedural constraints brought about by the inscription of action in a judicial context, since the judicial sequence follows a certain number of steps that - while they may well be formalized in the form of a sentence - nevertheless correspond to a series of empirically observable achievements, explicitly produced by the participants in the process. One of the major tasks facing a professional engaged in the routine exercise of his profession is to manifest publicly the correct performance of his work. The production of a procedurally impeccable sentence is one of the priorities to which legal professionals orient, and this is expressed to all public ends in the summary operated by the judge, the document of the judgment itself, and the effective accomplishment of all the legally necessary tasks. Most of the documents contained in a legal dossier translate this orientation of judges, prosecutors, and other professionals to this form of procedural correctness. This appears as directly linked to the general sequence of judgment, in which participants address people who are not necessarily physically present in the room, but who make up an audience that listens and, as it were, looks over the participants' shoulders - an audience that is virtually capable of invalidating procedure on a point of order. These procedural constraints, which the actors identify explicitly, do not correspond to a set of abstract rules drawn from an 
external legal system, with its own history and superior vantage point: rather, they correspond to the routine, bureaucratic dimension of people engaged in a variety of legal professions.

Procedural constraints aside, participants in legal interaction orient to what might be termed legal relevance. This indicates the qualifying operation that consists of bringing a factual instance into line with a formal legal definition. The qualifying operation may be endowed with a character of uncertainty, yet cannot be considered as totally problematic or arbitrary. The categories to which the judge refers have an objective nature, as far as the judge is concerned, even if it is qualification itself that makes them objective. Further, one may observe that the legal process of qualification depends narrowly on a sociological process of normalization, which designates all the operations through which the magistrate routinely selects some characteristics that belonged to a common, normal, or usual type in the case under consideration. Parties - the judges, prosecutors, lawyers, victim, accused, witnesses, etc. - therefore orient to these "normal" categories, which, even beyond their formal legal definition, belong to the realm of common sense. From this perspective, we must recognize that passing judgment operates as a justification, by identifying all the procedural and substantive rules that it satisfies, while dissimulating the practical character of its own constitution. It is possible, nevertheless, to measure these practical operations by reexamining the different stages through which they are formed, as well as the many documents that support the judge's work, and also by investigating the intertextual relation that brings them together.

The third part of the present work will put forth a sort of practical grammar for a number of legal epistemic themes. First, I will endeavor to reconstitute the doctrinal and jurisprudential background of Egyptian penal law. This will provide an opportunity to review textual legal formality, particularly with regard to questions of capacity, intentionality, and causality. I will highlight the vast distance between this type of textual documentation and the incarnate, lived conditions in which it is produced. To paraphrase Garfinkel, the normative enunciation of applied or implemented law finds itself in an asymmetrical relation to the detailed account of its practical, contextual elaboration, to the degree that the former dissimulates everything that contributed to its production, while the latter seeks precisely to reconstitute all the operations that led to the production of a formal, abstract document. While the different parties to a judicial process explicitly manifest their orientation to a certain number of rules of law, this does not mean that describing the mechanism of their orientation is strictly tantamount to simply enunciating the rule. 
Having established this point, the following chapter will examine the grammar of the legal concept of personality and its corollary, capacity. The physical person constitutes the reference point for practical legal reasoning. Far from being an abstract, inaccessible category, it is made public through the methodical deployment, in social interaction, of shared linguistic resources. References to someone's person provide the opportunity for the selection and production of descriptions that depend strictly on the activity underway. In other words, what a person is officially for someone else depends on the course of action being taken. The realization of personality as a category is a public phenomenon through and through, and is articulated around a schema: that of the normative, normal person. Garfinkel's study of the case of Agnes shows how sexual identity is continually produced and managed in the course of social and institutional interactions. Persons and their identity function as a background that is constantly being mobilized, although that background remains largely unexplained and is loosely defined. The capacity to be defined as a person therefore depends mainly on people's ability to present a normal appearance and to expect treatment from others on that basis. Among other methods used to this end, we must note procedural incongruity, which contrasts expected behavior with perceived behavior, and draws from their convergence or divergence certain consequences with respect to the person under consideration.

In this attempt to constitute a practical grammar of some concepts of penal law, I will turn, next, to causality. It is impossible, when dealing with this question, to dispense with the reference work by Herbert Hart and Tony Honoré, Causation in the Law. The authors of this work laid the foundations for an exploration of causal reasoning in law, and, in particular, of its strong links to common sense, as well as its contextual sensitivity. Nevertheless, I will try to demonstrate that this type of approach, while it helps us identify the parameters of causality in legal practice, is not able to explain precisely the phenomenon with which it is dealing. This is due first and foremost to the fact that the authors studied material that had already been abstracted, formalized, and polished, leaving in shadow all the practical, contextual, and situated production of causal affirmations at the different stages of the judicial process. Legal reasoning and common sense are articulated, in practice and in context, around different notions, such as cause, reason, motive, intention, excuse, justification, or circumstance. All these are notions to which people orient throughout the judicial sequence. Here, too, it is necessary to note the importance of underlying schemes of normalcy and naturalness, and the inferences drawn from their invocation with respect to the qualification of an incriminated action. 
A final chapter will deal with the practical grammar of intention. In penal law, intentionality is one of the central criteria in the work of judicial qualification. In this chapter, I will focus on showing how magistrates, and prosecutors in particular, organize their activities in practice around the establishment of this component of crime. After having painted a summary portrait of the literature that has dealt with this question in the field of legal theory, and after having pointed out the essentialist nature of previous approaches which seek to grasp intention as a philosophical notion, independent of the institutional context of its mobilization - I will adopt an approach that is consistent with praxiology, and look at the question of intentionality as the result of interactions situated in the institutional legal context. This context forces professional actors to orient to the production of a legally relevant decision. We will thus observe how profane actors adjust their behavior to the constraints of this institutional context, under the impact of induction carried out by professionals, and under the impact of their own anticipation, which causes them to act in such a way as to obtain (from the place and the people they are facing) the solution that will prove most favorable, least damaging, or at least most consistent with the routine achievement of their work.

In the fourth part of this work, I will undertake the praxiological study of a trial that rested on an operation allowing for the judicial definition of morality, among others. Whether the question is one of homosexuality, of prostitution, or of mental health, it is possible to observe and describe, in detail, the work of the various parties engaged before the courts in matters touching on morality. Here, morality is a constitutive part of a specific domain, to the degree that people orient to it as such. The so-called Queen Boat affair will provide a case study here. This part is organized in three chapters. First, I will specify the internal organization of the sentence as a specific text. In so doing, it will be possible to describe both the substance of the affair, in the formalization carried out by the judge, and the structure of the judgment, in its deployment on a specific occasion. Second, I will observe law and justice in action in moral questions of this type. This will lead us to examine in detail the conversational, sequential organization of judicial procedures in their entirety, without it being possible to affirm, pending further information, that their bearing on moral questions has the slightest influence on their outcome. Finally, I will undertake a category-based analysis of the interrogations enacted by the public prosecutor's office and the texts produced by various professional bodies. This will provide an opportunity to observe the modes whereby categories emerge and function, as well as their inferential properties. 
While the first three parts deal with the moral nature of ordinary legal reasoning, the practical dimension of morality, and the ubiquity of morality in the course of judicial activity, the three chapters of the last part focus on morality as a specific domain on which certain human activities come to bear, such as religion, ethics, morality, philosophy, and, most importantly for us, law. Discourse on morality depends wholly on what we have called the morality of cognition. In the fourth part, we will try to show how this morality is exercised on the occasion of the judicial treatment of moral questions, and what modalities preside over the deployment of this treatment.

In conclusion, we will return once more to the articulation of the morality of judgment and judgments bearing on moral questions. On one hand, legal activity does not necessarily have to bear on moral questions in order to be morally constituted, organized, and practiced; nevertheless, on the other hand, it is important to note that this same legal activity can occasionally take as its object questions that evidently belong to the domain of morality. It is no doubt necessary to observe and describe the ways in which the morality of judgment and judgments on morality can mutually strengthen and shape each other. However, to remain consistent with the praxiological approach, we will not seek to propose a model that might enclose within its contours the abstract configurations that such relations might follow in the concrete course of events. Rather, we will seek to highlight two mechanisms: first, how the judge's activity aims not only at transforming moral questions into legal matters, but also, because this activity is moral through and through, how it cannot strip the law of its specifically moral dimensions; second, how the domain of morality not only constantly informs law and serves as a basis for the establishment of judgment as normalcy, but also, because it is associated, and yet not assimilated, with the law, how it can never entirely replace the law or people's orientation to the different practical ends they impute to it.

\section{Justification of a non-culturalist stance}

Although this book is based on material taken from Egyptian legal activity, it must be clear by now that its aim is not to reveal the secrets of an "exotic" legal universe. On the contrary: it attempts to describe this activity without any prejudice with regard to what might distinguish Egyptian judicial space from other legal spaces. It does not even posit the existence of such differences. In other words, this book examines legal practice in an Egyptian environment, and not Egyptian culture observed through the prism of law. Actually, Egyptian culture is only one of the many components of the context in which the practices of Egyptian law are 
deployed - a context that is always unique, and never uniform. To suppose that this cultural component is primordial is to run the risk of not paying enough attention to other possible components, although, in practice, the members of the Egyptian judicial environment orient to many other things in the course of their actions. This also poses the threat of over-estimating the impact of culture; and yet, culturalism has untranslatability as its corollary. In this perspective, one could argue that a given concept, formulated in Arabic, cannot be perceived adequately in French or English, because its essence is accessible only in the language in which it was originally formulated. On the contrary, we consider that every phenomenon, whatever the language in which it is expressed, can always be translated into another language, and rendered accessible to observation and description. This implies, however, ' $[\mathrm{r}]$ ather than pretending to read a culturally standardized finished text over the shoulder of an imagined native, we will be living in the line-by-line production of ongoing actual native talk.' (Moerman, 1988: 5)

What justifies the use of Egyptian legal data, then, the reader might ask, if it is not to substantiate the affirmation of cultural difference? The answer is, first, that there is no reason to consider that a given context is automatically more relevant, appropriate, or worthy of interest than any other. Second, we would add that, if this book manages to show the similarity of context rather that their irreducible difference, it will have been worth the effort, in a general atmosphere where the common humanity of humanity seems to have been denied in the name of cultural conflict or a clash between ineffably different civilizations. Of course, some specificities can ultimately be attributed to the Egyptian cultural context, but they may no longer be considered untranslatable. On the contrary: 'their meanings are knowable and, of course, known: they are governed by grammatical conventions which are determinable, and form part of the conceptual endowment of the human species, notwithstanding their differential empirical distributions of actual usage and the different kinds of language-games played with them in different cultures.' (Coulter, 1989: 101) 